\title{
Advantages, Challenges and New Frontiers in Using Information Communication Technologies in Societal and Social Movement Research
}

\author{
Mayo Fuster Morell
}

mayo.fuster@eui.eu, European University Institute, Spain, www.onlinecreation.info

\begin{abstract}
This paper includes a review of the main methodological trends and methods related to ICTs adopted in social movement research. It then reflects on the advantages and challenges of using ICTs for research. Finally, it suggests potential and new frontiers in the use of ICTs for research.
\end{abstract}

Keywords: online methods, digital methods, methodological innovation, social movements, organic data

Acknowledgement: I would like to thank Louisa Parks for the English-copy editing of this article.

Information and Communication Technologies (ICTs) can be seen both as a field of research research on ICTs and society - and a channel for carrying out research - ICTs as methodological artifacts. Research has always depended on the dominant media matrix (Johns, Chen \& Hall, 2004), and ICTs represent the latest stage in this development. Although ICTs are rapidly evolving and still in an embryonic phase, some main tendencies can be identified.

The paper is built around a review of emerging methodological trends linked to ICTs, particularly in social movement research, and explores the potential of ICTs for research.

When using ICTs for research, it is necessary to consider the specific status and characteristics of the medium (Johns, Chen \& Hall, 2004) and remember that, as some researchers have pointed out (Hine, 2005), existing methods do not necessarily apply to ICTs. In this regard, two major approaches can be differentiated: online methods and digital methods. Online methods refer to the adaptation of existing methods to the online environment in order to "create" data (examples are virtual ethnography or online interviews), while digital methods are based on "following the medium". Digital methods approaches do not adapt existing methods to the study of online practices, but invent new ones more suited to the medium, using data available online rather than creating data (Rogers, 2009).

Hine highlights two major issues in the adoption of ICTs for research: innovation and anxiety (Hine, 2000).

Innovation refers to the fact that using ICTs for research is in itself an innovation. But Hine is also aware that this innovative aspect also represents a source of anxiety. Innovation necessarily involves breaking down old, reliable, and established modes of research, leaving a field of experimental settings and unproven methods. Anxiety in ICT research most often arises from the notion "that nothing can be taken for granted", especially since netiquette in general in ICTs, and the ethics of online research - as a new form of social interaction, both for researchers and the researched - seem to be a prime issue in which anxieties play a role (Hine, 2005; Zurawski, 2006).

Another feeling that is regularly transmitted by researchers involved in using ICTs is the enthusiasm involved.

As Rutter and Smith put it in "Ethnographic Presence in a Nebulous Setting", "the definition of the research setting becomes not a starting point but a primary research question requiring careful and continuous examination" by the researcher throughout the fieldwork (Rutter \& Smith, 2005, p. 85). 


\section{Four Different Types of Relationships Between Research Goals and ICTs}

As a preliminary step, in this section I will reflect on the relationship between ICTs and research. I distinguish four types of relationship here.

As previously mentioned, the use of ICTs for research and research into the socio-culturalpolitical implications of ICTs are two different things. That is, the research method and object do not necessarily have to go together. However, it is common for research on ICTs and society to develop some type of online ethnography, and the work frequently adopts other ICT methods. The use of ICTs to research the implications of ICTs in society or the use of ICTs by various social actors is the first type of relationship between ICTs and research. This is for example the case of researching how social movements use Facebook by carrying out virtual ethnographies on Facebook.

The second type is the opposite of the first, that is the use of ICT methods to research issues unrelated to ICT questions. However, the use of ICT methods for the research of questions, which are not linked to ICTs, is less frequent. For example, when the goal of the research is to extract the participant of a demonstration's sociological profile or offline action repertoire, the use of ICT methods is not frequent, and usually traditional methods of social movement research such as surveys will be found.

A third type is research that utilizes ICTs as indicators; for example, the adoption of hyperlinks as indicators for connections between organizations. In this case, the online dimension of the actors is not the major focus of the work, but is used as an indicator for some quality.

Finally, perhaps the most common occurrence is for researchers to use ICTs for approaching a research object, such as visiting an actor's website to gain a first impression or obtain contacts, or to communicate with his or her informants in order to agree on the development of "offline" research methods.

Before continuing, it may be worth clarifying that the categories of online and offline, (or according to the terms used in this paper: ICTs for research versus research independent of ICTs) must be used with caution. Online generally refers to any interaction mediated by a computer; while offline is considered as anything, which does not fit the definition of, online and involves physical interaction. However, there is an ambiguous area between the two. An interview can be carried out on a mobile phone, for example, and it is unclear whether this should be considered online or offline. As NTI are further adopted, it is difficult to find purely offline or online situations. In conclusion, I consider these categories part of an historical transition in the adoption of NTI, which may well become meaningless relatively quickly.

\section{Methodological Approaches and Methods Using ICTs to Research Social Movements}

In this section, I will present the emerging methodological approaches and methods using ICTs applied in social movement studies, and the main conclusions drawn on the subject thus far.

\subsection{Website Analysis: Statistical Analysis of the Characteristics of Social Movement Organiza- tion Websites}

This approach is based on large $N$ statistical comparative analyses of the characteristics of social movement organizations' websites. It builds on the literature on democratic quality (BergSchlosser, 2004; Bollen, 1990; Bollen \& Paxton, 2000; Diamond \& Morlino, 2004; Morlino, 2004; Munck \& Verkuilen, 2002). The empirical research using this approach was first developed with a focus on political parties' websites (Davis, 1999; De Landtsheer, Krasnoboka, \& Neuner, 2001; Gibson, Nixon, \& Ward, 2003; Norris, 2003; Römmele, 2003; Trechsel et al, 2003). It then moved on to examine non-conventional political actors such as Non Governmental Organizations (NGOs) (Vedres, Bruszt \& Stark, 2005a, 2005b), social movement organizations (della Porta \& Mosca, 2006, 2009; Sudulich, 2006; Van Aelst \& Walgrave, 2005) and blogs on civic engagement (Navarria, 2007). 
One research design aspect common to web analysis research is that researchers do not "try to deduce social effects from the properties of technologies" (Vedres, Bruszt \& Stark, 2005). According to this body of literature, actors model their use of the Internet to their own styles, organizational strategies and logics (Vedres, Bruszt \& Stark, 2005).

In Searching the net: the Democratic qualities of the Internet, della Porta and Mosca (2006, 2009) statistically analyze social movement websites, extracting several styles of democratic quality by considering dimensions such as the provision of information, identity building, external accountability, mobilization, and the reduction of user inequality (digital divide). The different website styles reflect different models of democracy (and democratic communication) present in social movement organizations (della Porta \& Mosca, 2006). The important point in this research is that not all dimensions are correlated: this confirms that organizations choose the maximization of some, but not all, dimensions of democracy.

The data collected by della Porta and Mosca $(2006,2009)$ was developed by a team of coders, that is, researchers visited 261 social movement organization website and checked for the presence or absence of lists of elements considered indicators of democratic quality. When visiting the websites, the coders also reported on particular aspects relevant to the sites. This work highlights the difficulties of coding a large variety of websites and potentially relevant elements in those websites, pointing out the importance of having a clear notion of the focus, yet leaving space for comments on questions not considered initially, and the necessity of verifying coding carefully before starting data collection.

Another example of website analysis is the study by Sudulich (2006) on a sample of websites of protest networks and pressure groups. Sudulich analyzes these websites by focusing on two indicators: their capacity for web connectivity and the potential for bilateral/multilateral communication they offer to users as compared with information provision. The conclusion is that one-way communication is more developed and more sophisticated than two-way communication. The level of two-way communication (participatory instruments) was rather poor. Moreover, no evidence emerged of statistically significant differences between big and small organizations on those issues, although bigger movements have better online visibility (number of links) than smaller ones.

Finally, I adopted the web analysis approach to research 50 online communities linked to the free culture movement (Fuster Morell, 2010). However, in developing my analysis, I identified a limitation. As previously presented, the research approach to the democratic quality of nonconventional actors is inspired by the literature on the democratic quality of Nation-States and the web analysis of political parties and public institutions. In this regard, the set of dimensions of democratic quality contained in the literature are more suited to an organizational logic of representation than to an organizational and democratic logic, which is not representative, as is the case for social movements and NGOs. Methodologically, it was challenging to define indicators applicable to 50 different cases. Additionally, the main restriction on data collection was physical. The collection of data to fill the codebook was very tiring, and potentially harmful to the eyes, meaning that long sessions of data collection of digital threads could not be undertaken. The time required for data collection is thus necessarily lengthy.

\subsection{Social Network Approaches to Analyzing the Web Hyperlink Structures of Social Move- ment Networks}

Another significant approach is based on a social network meso-reticular approach to analyzing the web hyperlink structures of social movement networks. Diani (2004) takes the links between a social movement website, among other sets of indicators both online and offline, as a reticular indicator of the existence of social movement networks, in order to extract their form and the structural positions and influence occupied by each organization in the network. Accordingly, Diani argues that SMOs should be identified first of all by their network position, rather than by their characteristics as organizations.

Koopmans and Zimmermann (2007) examine hyperlinks in order to extract the visibility of an organization through the role of search engines and communication networks that have emerged on 
the Internet. In this sense, the website of the most "hyperlinked" organization also turned out to be the most visible. Concerning this reticular network analysis, the analysis is focused more on interorganizational than intra-organizational aspects.

Yet this trend does not directly address the use of ICTs by social movements. Instead, this research examines uses of the Internet as indicators of something else (i.e. hyperlinks as indicators of connections between organizations), while the online dimension of the social movements is not the major interest.

\subsection{Content Analysis of E-Lists}

An example of the content analysis of e-lists trend is the analysis of the role of these in the preparation of the European Social Forum (ESF) in London (October 2004) by Kavada (2007). The ESF has been the main meeting point of European social movements since 2002. Kavada combined the analysis of the e-mail exchanges in the e-list with participative observation at the ESF preparatory meetings and in-depth interviews with activists. She concluded, among other aspects, that e-lists played a major role in the preparation of the decisions, but decisions were made in offline spaces. In this sense, Kavada (2007) points out the importance of combining offline and online dimensions of analysis.

Another example is the content analysis of e-lists on the G8 counter summit in Genoa in July 2001 carried out by Calderaro (2010). Calderaro highlighted the greater difficulties encountered when coding e-lists in comparison to website coding. According to Calderaro, the major difficulty of coding e-lists is due to the amount of e-mails circulating; the large and subtle typologies of e-mail interventions in the e-list; and difficulties in identifying the subjects - units participating in the conversation without any "image" and different degrees of participation. Apart from the major difficulties, this experience also highlighted the richer data resulting from e-list analysis when the goal is to understand the networking and discussion taking place in a political process (Calderaro, 2010).

\subsection{Online Surveys of Social Movement Participants}

Online surveys refer to surveys or questionnaires made available at a website. Informants are invited to go to the website and fill in the questionnaire. An example of the online survey is the online participant survey carried out at the ESF in Athens (October 2006) by the Media, Movements and Politics research group of the University of Antwerp ${ }^{1}$. This experience points out the potential problems of using online surveys to reach activists.

At the Athens ESF, paper versions of the online questionnaire were also distributed (about 600 ), but only 68 were received immediately. In order to get more people involved via the website afterwards, leaflets were handed out at the ESF with a short (appealing) message and the URL of the online questionnaire. An e-mail was also sent to the ESF mailing lists to invite people to participate (about 700 subscribers) and an e-mail sent to about 1500 e-mail-addresses (from ESF participants who registered through the ESF website). The result was an interesting data file containing 510 respondents. An advantage of this online survey is that the 510 answers are already inserted in a database format and the researchers did not need to insert the answers corresponding to each question. The costs were not very high as Internet communication is not very costly, but the number of activists reached is relatively low considering the number of activists contacted. Apart from these advantages, it is useful to reflect on the problems identified during this experience: the problems of over-representation of some collectives (in this case those that received the e-list invitation directly), the possible bias of contacting those activists more connected online and those knowing English (the survey was only in English and the ESF e-list uses mostly English), and with almost half of the questionnaires (200) incomplete, possibly because the questionnaire appeared too long in an online timing perception.

\footnotetext{
${ }^{1}$ More information on the Online Survey of the ESF participants can be found at http://www.m2p.be
} 
Jeroen Van Laer, a researcher involved in developing the survey, concluded that "whether you had better use online questioning or not clearly depends on what you want to ask to people and which kind of people you want to reach" (J. van Laer, e-mail interview, 25 March 2007).

\subsection{Online Interviews}

In social movement studies, phone interviews have been used on those occasions when for several reasons offline interviews could not take place. Nowadays, the substitute for the physical interview can also include e-mail, video-conference or chat interviews. In other cases, online interviews are not a substitute, but the first choice for researchers for a variety of reasons.

With the development of ICTs, visual and audio communications gained in importance. But in 2010 a major characteristic of ICTs is the predominance of textual communication. This format influences the contents extracted from the communication. For example, e-mail interviews may be different in style, temporal dimensions and the sense of intimacy and trust established in the process compared to a face-to-face interview (Kivits, 2005). But where the peculiarities of textual communication are borne in mind, textual communication can be as rich as a face-to-face a experience.

However, obtaining online interviews is not always easy. The level of responses to interviews by e-mail, following van Laer's previous reflections (J. van Laer, e-mail interview, 25 March 2007), depends on the profile of activist the researcher wishes to reach. In research on social movements highly related to the Internet (such as the free software movement or the communication rights movement) communication through e-mail is very frequent, even when activists are in the same physical space. The frequent use of e-mail communication between activists in those movements could explain why the responses to online methods among these types of activist are more positive. For example, in my own research on the "Wiffi communities and Uses of collaborative wiffi among neighbors in the Spanish State", I used e-mail interviews as a main method, combined with website and e-list observations, with the goal of establishing the technological equipment and sociological profiles of the users. In this case, the number of answers to the request for an e-mail interview (without any previous contact) was very high and characterized by the accessibility of the activists (Fuster Morell, 2005).

However, researchers of online communities, a population familiar with computer-mediated communication, mention that soliciting online interviews to engage participants in online communities generally results in poor response rates (Reagle, 2005). From my experience of interviewing members of four online communities (2010), the most effective procedure to secure online interviews was to attend offline meetings. Another good method was to ask the people I interviewed to put me in contact with others I wanted to interview. In my view, the higher response rates of informants in offline meetings are mainly related to gaining trust and attracting the attention of the informants. With other forms of gaining the trust and attention of informants, developing case studies using only online methods may also work.

\section{Advantages and Challenges of ICTs Research}

After reviewing the main approaches in the adoption of ICTs for research, in this section I will reflect on the advantages and disadvantages of adopting ICTs for research.

\subsection{Advantages of ICTs in Research}

\subsubsection{Technically We Have a Larger Variety of Options}

Although most ICT communication is textual and asynchronous, technically, focus group research or interviews using ICTs can be carried out in various modes, allowing for all kinds of communication - textual as well as visual, synchronous as well as asynchronous. 


\subsubsection{Reduction of Potential Costs, No Need to Place People in a Physical Location and Environmentally Friendly}

ICTs are generally less costly than other technological communications (such as the telephone) and physical encounters. It also reduces the paper required and the environmental impact of the research.

\subsubsection{Possible Recombination of the Data}

The digitalization of the data and access to powerful machines allows data to be recombined in several manners.

\subsubsection{Research Without Borders}

There are no geographical or distance constraints. For example, if you are using online methods to analyze the Christiania community - Copenhagen is as close as the social center Can Mas Deu in Barcelona.

\subsubsection{The Time-Consuming Procedure of Transcribing the Discussions Is Avoided (With Textual Data)}

But communication mediated through computers also poses other major challenges.

\subsection{Challenges of ICTs in Research}

In this section, the challenges of ICTs used for research as pointed out by researchers will be presented. Suggestions on how to overcome these challenges will also be proposed.

\subsubsection{Establishment of Trust and Identification of Actors Through ICTs}

The establishment of trust and identification of actors through ICTs, a medium where the researcher usually remains distant and faceless as compared to face-to-face communication, and where most non-verbal communications is lost, constitutes a major challenge.

For research transparency and trust-building one relatively common possibility is to build an online reference space such as a website where the research is presented. Another option is to become useful for your subject of research, for example by sharing systematized data. Last, a positive sign from a social movement point of view is to use free software, as progressive social movements tend to be supportive of this.

Online communication is also difficult in terms of the identification of the informant for the researcher, as it is possible the researcher will only have a name or nickname and an e-mail address or a URL as reference points for his or her informant. Furthermore, if the actor is a member of an online collective (such as an e-list), there are some difficulties discerning the boundaries of the groups due to the general openness of the online spaces and the lack of a "visual" image.

\subsubsection{The Trap of Techno-Enthusiasm: The Need to Adapt Technology to the Research Tar- get}

An ICT research tool might work technically, however this does not guarantee that it is adapted to the expected audience. Adapting the technology of the method to the ICT behavior of the subject is therefore necessary. One aspect to consider that could affect the use and response to the online method is reflecting on the informant's approach to ICTs. Another aspect to consider is the level of technological education of the population the researcher is addressing, and also to play the virtual personality of the person. There are people very fast when interacting through ICTs, and there are people who are slow. 


\subsubsection{Representativeness of the Sample, New Sources of Bias and the Digital Divide}

Participation in a method available online (such as a survey) could be restricted to specific people or it could be open to anyone. In the second option, the spreading policy is very important, because the spreading policy will guide the people arriving at the site. But importantly in open surveying, there is a risk of losing control over the representativeness of the sample.

Concerning the digital divide, according to some authors, social movement participants are not particularly affected by the digital divide. Instead, a very high percentage of activists access ICTs and they display higher connectivity than the general population (della Porta \& Mosca, 2006). But it is a contextual element that needs to be considered.

There is also the risk that most of the time the researcher will only contact some types of ICT approaches, that is, people more technically educated or the enthusiasts in an organization.

\subsubsection{Possible Surprises With Research Timing, Not Necessarily Short}

When the researcher depends on the interactivity of the informants, ICT methods do not necessarily reduce the time required for the data collection. Especially when using asynchronous methods, a lot of time is spent being the timekeeper; that is, in reminding informants to send information. For example, if we ask for an e-mail interview, one element worthy to consider is that, as could happen to the researcher him/herself, the person addressed could be swamped by e-mails. It may even happen that the person thinks the request is spam. A possible way to "block time" for online methods that require the interaction of the informant, like online questionnaires or e-mail interviews, is fixing a "date" when the researcher is also present on Skype or another instant messaging system. This way, the researcher can provide support to the informant while he or she answers the questions should something be unclear.

\subsubsection{The Problem of Data Overload and the Selection of Relevant Data}

We can acknowledge that with ICT methods the researcher is able to get large quantities of field notes, as much information is recorded and available. However, this raises a well-known problem for online researchers - namely, that of information overload. The online researcher faces a problem in selecting relevant information. In this regard, it is important to go online with a clear and disciplined outline of the concrete data required. ${ }^{2}$

\subsubsection{Do Not Completely Ignore the Offline Dimension}

The use of ICTs does not completely override the need for physical encounters with informants. If the social movement action combines physical and virtual presences, it is highly recommended to meet both through ICTs and in the physical world (Kavada, 2006). Moving between the on- and offline spheres is a research advantage, for it provides different levels of explanation, thus adding depth to a given study. Additionally, in order to get responses online meeting informants can help to increase the response rate.

\subsubsection{Technological Dependence}

To use ICT methods the researcher needs to know to use them technically, otherwise he or she must depend on the technical knowledge of others. To use email, e-list or chat-forums might be easy for a researcher. But to build a website is more complex. New software, like the technology of the Web 2.0, has reduced technological dependence, but websites require more expert knowledge support.

Another aspect to solve is choosing the strategy for the software to be used. As one ICTs researcher explains

\footnotetext{
${ }^{2}$ Furthermore, NTI facilitates the spreading and sharing of research data among scholars, which contributes to the availability of large amounts empirical data for the development of research.
} 
"Concerning software, there are plenty of tools but personally I'm not satisfied with them because they are customized towards very specific ends. If you can handle SQL (Database), then you could construct yourself everything you need" (M. Boudourides, e-mail interview, 25 March 2007).

But then the researcher needs to have the skills to design new tools or customize available ones. Finally, the sustainability of those tools implies some costs (URL, server space, technical maintenance, among others).

\section{Potential Developments of ICT Research}

This section will present some potential developments of the use of ICTs in social movement research.

\subsection{Expansion of ICT Methods and of the Research Object}

I expect an expansion in the use of ICT methods in social movement research. The expertise in ICTs of younger generations of social movement scholars and the increased use of ICTs by social movements could explain this tendency. Furthermore, this tendency could be accompanied by an expansion of the research object to consider mainly Internet-based social movements not necessarily having any previous (mainly offline) existence.

\section{2. "Interactiving" the Methodology and Results: Research $\mathbf{2 . 0}$}

ICTs have several technological generations. The latest ICT tendency is found in the concept of the Web 2.0.. The Web 2.0, proposed initially by O'Reilly (2005), refers to a second generation of ICTbased services - such as social networking sites, wikis, and communication tools - that emphasize online collaboration and sharing among "users" to build the site content. It also differs from early Web development (retrospectively labeled Web 1.0) in that it moves away from static websites, the use of search engines, and surfing from one website to the next, towards a more dynamic and interactive World Wide Web.

Coming back to ICT research matters, ICTs and the World Wide Web facilitate the establishment of a channel for a more continuous relationship with informants. It is possible, and is the practice of some researchers, to build a website around the research containing information about the project's development. Moving forward, the Web 2.0 opens possibilities to develop more participative and collaborative research methodologies. As part of its layout, a Web 2.0 site can allow, through mechanisms of interactivity and easy intervention, informants to provide data for the empirical research directly or/and interpret and debate the data and results themselves.

In this sense, the phenomenon known as "techno-political tools" (Fuster Morell, 2007) is already emerging in the social practices of social movements and process of social transformations. Techno-political tools refer to a strategy and a rich variety of experiences shedding light on decentralized swarming, collaborative and open environments on the systematization and interpretation of the knowledge generated by mobilization processes. Those experiences are based on Web 2.0 websites in order to collaboratively and participatively build the memory of the social movement. For example the Forum Pedia's slogan: "A collective narration and report about the social forums and from the point of view of the social forums participants" ${ }^{3}$. One of the challenges for the application of these experiences to research would be to combine this open research methodology with the rigor and the distant view of the results of the social research.

\footnotetext{
${ }^{3}$ Forumpedia available at http://www.euromovements.info/yearbook
} 


\subsection{Towards a "Non Artificial" Methodology: Digital Threads or Organic Research Data- bases}

In the ICT sphere all actions are translated into digital information, and digital information always leaves a trace in databases. A growing part of the daily lives in the global North and developed countries passes through digital supports (PCs and other machines). All this growing information generated in daily life can be connected and interpreted by programs, ever more complex, in order to extract applicable knowledge.

This mass of information produced as a consequence of actions designed for other ends has become a contended source of searches and analysis and can be used to produce very sophisticated knowledge. In this regard, "organic data" refers to the collection of digital threads available online, or the observation of the public practices and discussions that the cases generate in their daily on and offline lives without external intervention. For example, the analysis of e-mails exchanged in public mailing lists among the participants in the cases. Most of the online activity of social movements is publicly available and recorded, so there is an abundance of data available on social movement practices without the researcher needing to use methods to "create" data, in the line of the digital methods approach (Rogers, 2009). ${ }^{4}$

The treatment, accessibility, privacy, security, and legality of organic data is at the center of many current debates. There are many limitations on the use of these data, which invade privacy and include detailed information on everyday behavior. This source of information and knowledge is already exploited for surveillance and commercial aims, and these are based on solutions that allow the bypassing or simply ignore legal restrictions.

Two examples of the commercial type are center cards and Google mail. Both buy the possibility to store and elaborate these information threads by paying "something" to the users (a gift after a certain number of purchases or free services). In this way they use the "natural" behavior of the users to elaborate marketing profiles.

No legal restrictions apply when the organic data are public, and this kind of "indirect" strategy to get and elaborate information and knowledge is beginning to be utilized in other fields of search, such as social movement studies, as previously mentioned: i.e. in the analysis of mailing list debates, in web content analysis, in the analysis of links etc.

This is probably a new frontier in the research: the possibility of storing and elaborating information produced independently of direct research aims (M. Berlinguer, Interview, 25 March 2007). Aside from many other complex (legal, social, cultural, political) aspects, the interest in the potential of this information will produce a close correlation between the development of the databases and protocols that organize the flow of any action in the ICTs and the aim of getting more and more information that can potentially be transformed into useful knowledge.

This strategy has already been introduced in the social forums process by its organizers, for example, by building a directory of 5.000 European organizations by systematizing the organizations registered at the several European social forums. Data normally produced by the actions necessary to organize the forum are now stored, saved, made easily accessible and utilized to offer further opportunities to produce knowledge and information and to intensify the networking process within and around this important space of confluence of social movements ${ }^{5}$.

Methodologically this strategy does not use ad hoc, "artificial" actions aimed to get information, but uses the information created by "autonomous" and independent actions to get large amounts of "empirical" data, potentially transformable into new knowledge.

\footnotetext{
${ }^{4}$ This invisible character is also under a growing, and worrying, network of "vigilance" developed by the Intelligence Agencies in alliance with Communication Companies (Calenda \& Lyon, 2007).

${ }^{5}$ See the directory of European organizations at: http://www.euromovements.info/directory/
} 


\subsection{Transdisciplinarity}

There are several aspects, which suggest that the use of ICTs in research will lead to more crossdisciplinary social movement research.

First, the design of ICTs as research tools requires a variety of skills. Researchers need to know to use research methods, but also have the skills and capabilities to design technical tools. In this regard, in the use of ICTs to research online communities the formation of research groups with several profiles (data analytics, designers and engineers) is frequent. In order to profit from this frontier, it would be useful for research centers and departments to build alliances and create the conditions for the technological support of the research. However, the need to find solutions for social scientists and engineers to work together in cross-disciplinary groups is probably one of the biggest challenges in the field, as many have reported the difficulties encountered in these types of groups.

In this regard, Lampe argues for a new approach combining the strengths of social and technical approaches to create a new epistemology of socio-technical systems. According to Lampe, social scientists tend to look at participation in these sites from the perspective of traditional social theories, and underplay the importance of technical features by dismissing it as "technological determinism". Engineers and computer scientists tend to build new systems and explain current ones without the benefits of theories that create a persistent epistemology across studies or systems. Climp suggests the importance of creating combinations of both (C. Lampe, keynote intervention at the International Symposium on Wikis and Open Collaboration, 2010). ${ }^{6}$

Second, in those cases where researchers use organic data available on the web (and do not build a specific tool to collect data), the larger possibilities opened up by the use of organic data might suggest a tendency towards an alliance between researchers and providers and designers of online infrastructure. The sensitive character of the organic data and the necessity to get permission and access to use them imply an intrinsic alliance between the providers and designers of online infrastructure and social scientists. Furthermore, social research can contribute to help infrastructure designers design tools in ways that generate more useful organic data for research needs. Both where the providers of online infrastructure are commercial companies and/or social movements, the use of organic data might imply the creation of an alliance between social researchers and commercial companies over online services or social movements as online infrastructure providers.

Third, the research on Internet-based collective action (such as online communities) is leading to cross-disciplinary research. Fields like Computer Science, Information Science, Communication, Sociology, Psychology, Law and Business have all been addressing the questions of new forms of collective action emerging on the Internet. This leads us to suspect that with the expansion of social movement research to Internet-based social movements, research might combine the theoretical frames of social movement theory with those of other fields (such as communication studies) in order to address this new phenomenon.

\section{Conclusions}

On the one hand, because ICT research is a very innovative research methodology, caution may be advisable. In this regard, adopting a multi-method approach could help. In this sense, Kleinman (2004) claims that a multi-method approach is necessary and useful in order to grasp the complexity of social phenomena.

In multi-method approaches, especially ethnographic methods, ICTs are important and valuable tools, even when applying seemingly simple methods such as hyperlink analysis and map visualization (Zurawski, 2005).

But even though the researcher needs to establish pre-defined categories and a methodological plan to guide the research, when using ICTs the researcher should be more prepared than when

\footnotetext{
${ }^{6}$ Further information on C. Lampe keynote intervention at: http://www.wikisym.org/ws2010/Invited+speakers
} 
using well known methods to deviate from the chosen course should new and unexpected insights and revelations crop up.

In this sense, in order to profit from the great potential of ICT research and to learn from innovative applications in other fields, it is worth incorporating an open and experimental spirit into the research and to avoid restricting the methodology to already known and proven options.

In conclusion, ICT research should be approached with the search for an equilibrium between prudence and experimentation.

\section{References}

Berg-Schlosser, D. (2004). The Quality of Democracies in Europe as Measured by Current Indicators of Democratization and Good Governance. Journal of Communist Studies and Transition Politics, 20(1), 28-55.

Bollen, K. A. (1990). Political Democracy: Conceptual and Measurement Traps. Studies in Comparative International Development, 25(1), 7-24

Bollen, K. A. \& Paxton, P. (2000). Subjective Measures of Liberal Democracy. Comparative Political Studies, 33(1), 58-86.

Calderaro, A. (2010). Empirical Analysis of Political Spaces on the Internet: The Role of E-Mailing Lists in the Organization of Alter-Globalization Movements. International Journal of E-Politics (IJEP), 1, $73-87$.

Calenda, D. \& Lyon, D. (2006). Culture e Tecnologie del Controllo: Riflessioni sul Potere nella Società della Rete. [Culture and Technology of Control: Reflexions about the Power of Network Society] Rassegna Italiana di Sociologia, 4, 583612.

Davis, R. (1999). The Web of Politics: The Internet's Impact on the American Political System. Oxford, UK: Oxford University Press.

De Landtsheer, C., Krasnoboka, N., \& Neuner, C. (2001). La Facilidad de Utilización de los Websites de Partidos Políticos. Estudio de Algunos Países de Europa del Este y Occidental [The Facility of Use of Websites of Political Parties. Study of Some Countries of Western and East Europe]. Cuadernos de Información y Comunicación (CIC), 6, 107140.

della Porta, D., \& Mosca, L. (2006). Report on WP2 - Searching the Net. Project Democracy in Europe and the Mobilization of Society. Retrieved from http://demos.eui.eu

della Porta, D., \& Mosca, L. (2009). Searching the Net. Web Sites' Qualities in the Global Justice Movement. Information, Communication \& Society, 12(6), 771-792.

Diamond, L. \& Morlino, L. (2004). The Quality of Democracy. An Overview. Journal of Democracy, 15(4), 20-31.

Diani, M. (2002). Network Analysis. In B. Klandermans \& S. Staggenborg (Eds.), Methods of Social Movement Research. Minneapolis: The University of Minnesota Press.

Diani, M. (2004). Cities in the World: Local Civil Society and Global Issues in Britain. In D. della Porta \& S. Tarrow (Eds.), Transnational Protest and Global Activism. Lanham (MD): Rowman \& Littlefield.

Fuster Morell, M. (2005). El Activismo Asociativo Pro-Wifi en el Estado Español [Pro-Wifi Associacionism Activism in the Spanish State]. Archivo Observatorio para la CiberSociedad. Retrieved from http://www.cibersociedad.net/archivo/articulo.php?art=210

Fuster Morell, M. (2007). Strumenti Tecno-Politici. In Transform! Italia, Parole di una Nuova Politica (pp.113-121). Roma: Edizioni XL.

Fuster Morell, M. (2010). Governance of Online Creation Communities: Provision of Infrastructure for the Building of Digital Commons. (Unpublished dissertation). European University Institute, Florence.

Gibson, R., Nixon, P. \& Ward, S. (Eds.) (2003) Political Parties and the Internet. Net Gain? New York and Londres: Routledge.

Hine, C. (2000). Virtual Ethnography. Thousand Oaks, CA: Sage.

Hine, C. (Ed.) (2005). Virtual Methods: Issues in Social Research on the Internet. Oxford, UK: Berg.

Johns, M. D., Chen, S. S. \& Hall, G. J. (Eds.) (2004). Online Social Research: Methods, Issues, and Ethics. New York: Peter Lang.

Kavada, A. (2006). The 'Alter-Globalization Movement' and the Internet: A Case Study of Communication Networks and Collective Action. Paper presented at the Cortona Colloquium 2006-Cultural Conflicts, Social Movements and New Rights: A European Challenge, Cortona, Italy.

Kavada, A. (2007). Email Lists as Multiple Sites of Identity Construction: The Case of the London 2004 European Social Forum. Paper prepared for the Symposium Changing politics through digital networks: The role of ICTs in the formation of new social and political actors and actions, Florence, Italy.

Kivits, J. (2005). Online Interviewing and the Research Relationship. In C. Hine (Ed). Virtual Methods: Issues in Social Research on the Internet. Oxford, UK: Berg. 
Kleinman, S. (2004). Researching OURNET: A Case Study of a Multiple Methods Approach. In M. D. Johns, S. S. Chen, \& G. J. Hall (Eds.). Online Social Research: Methods, Issues \& Ethics. New York: Peter Lang Publishing Inc.

Koopmans, R. \& Zimmermann, A. (2007). Visibility and Communication Networks on the Internet: The Role of Search Engines and Hyperlinks. In C. De Vrees \& H. Schmidt (Eds.), A European Public Sphere: How Much of It Do We Have and How Much Do We Need (pp. 213-264). Mannheim: Connex.

Morlino, L. (2004). What is a 'Good' Democracy?. Democratization, 11(5), 10-32.

Munck, G. L. \& Verkuilen, J. (2002). Conceptualizing and Measuring Democracy. Evaluating Alternative Indices. Comparative Political Studies 35(1), 5-34.

Navarria, G. (2007). Reflections on beppegrillo.it: A Successful Attempt of Innovation and Active Promotion of Political Participation Through the Web?. Paper prepared for the 4th ECPR General Conference, Pisa (Italy), 6-8 September, 2007. Section: "Emerging Patterns of Collective Action" Panel: "The use of ICTs for innovative forms of participation".

Norris, P. (2003). Preaching to the Converted? Pluralism, Participation and Party Websites. Party Politics, 9(1), 21-45.

O'Reilly, T. (2005). What is Web2.0? Design Patterns and Business Models for the Next Generation of Software. Retrieved from http://www.oreillynet.com/pub/a/oreilly/tim/news/2005/09/30/what-is-web-20.html

Reagle, J., Jr. (2005). Do as I do: Leadership in the Wikipedia. Retrieved from: http://reagle.org/joseph/2005/ethno/leadership.html

Römmele, A. (2003). Political Parties, Party Communication and New Information and Communication Technologies. Party Politics, 9(1), 7-20.

Rutter, J. \& Smith, G.W.H. (2005). Ethnographic Presence in a Nebulous Setting. In C. Hine (Ed.), Virtual Methods: Issues in Social Research on the Internet (pp. 81-92). UK: Berg.

Sudulich, M. L. (2006). ICT and SMO: Something New?. Paper presented at the "Cortona Colloquium 2006 - Cultural Conflicts, Social Movements and New Rights: A European Challenge", 20-22 October 2006, Cortona, Italy.

Trechsel, A., Kies, R., Mendez, F. \& Schmitter P. (2003). Evaluation of the Use of New Technologies in Order to Facilitate Democracy in Europe: E-Democratizing the Parliaments and Parties of Europe. Retrieved from http://www.erepresentative.org/docs/6_Main_Report_eDemocracy-inEurope-2004.pdf.

Van Aelst, P. \& Walgrave, S. (2004). New Media, New Movements? The Role of the Internet in Shaping the Anti Globalization Movement. In W. Van De Donk, B. Loader, D. Rucht \& P. Nixon (Eds.), Cyberprotest: New Media, Citizens and Social Movements. London: Routledge.

Vedres, B., Bruszt, L. \& Stark, D. (2005a). Organizing Technologies: Genre Forms of Online Civic Association In Eastern Europe. The Annals of the American Academy of Political and Social Science 597, 171-188. doi: $10.1177 / 0002716204270504$

Vedres, B., Bruszt, L. \& Stark, D. (2005b). Shaping the Web of Civic Participation: Civil Society Websites in Eastern Europe. The Journal of Public Policy, 25, 149-163.

Zurawski, N. (2006). Review: Hine, C. (Ed.). (2005). Virtual Methods: Issues in Social Research on the Internet. Oxford, UK: Berg Publishers.

Interviews cited:

M. Berlinguer, Interview, 25 March 2007.

M. Boudourides, Not structured e-mail interview, 25 March 2007.

J. van Laer, Not structured e-mail interview exchange, 25 March 2007.

\section{About the Author}

Mayo Fuster Morell,

Mayo recently concluded her PhD thesis (Title: Governance of online creation communities. Provision of infrastructure for the building of digital commons) at the European University Institute in Florence (2006-2010) under the supervision of Professor Donatella della Porta. She analyzed models of governance of common-based peer production and the relationship between governance, participation size and collaboration complexity. She is currently a Berkman fellow. At the Berkman Center, she is part of the Cooperation group overseen by Yochai Benkler. She will be researching the dimension, evolution and governance of common-based peer production; and the meta-politics derivatives and movement of free culture and digital commons. Furthermore, she is a member of the steering committee of the Internet and Politics Standing group of the European Consortium of Political Science (ECPR); and the Research Committee of the Wikimedia Foundation. A part of her research in the area, she was promoter of Networked Politics collaborative action research (www.networkedpolitics.info), co-foundered and organized the 2009 and 2010 editions of the International Forum on access to knowledge and digital rights (http://www.fcforum.net) and is promoter of the Building Digital Commons Forum (http://www.digitalcommons.net). Personal website with access to publications: http://www.onlinecreation.info 